\title{
Thermal analysis of non-actinide bearing
} salt

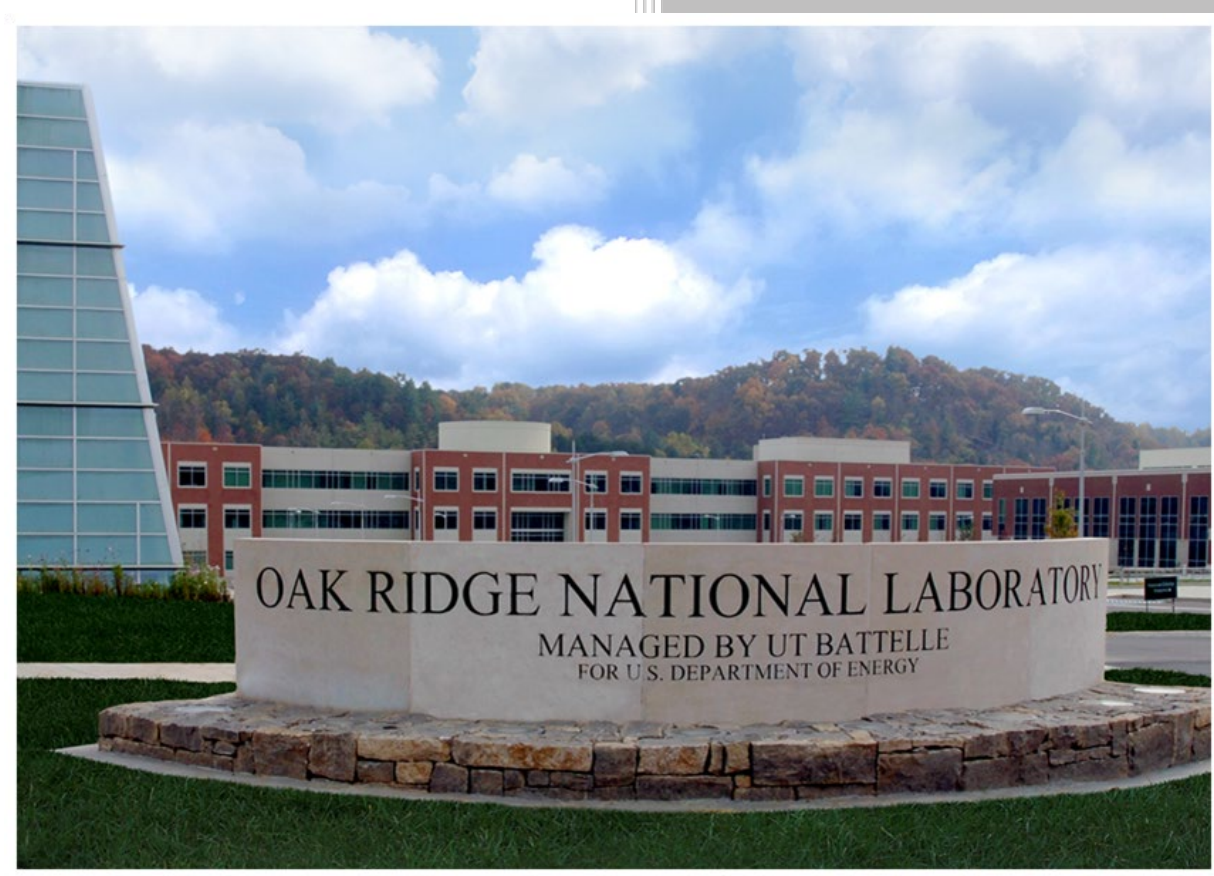

J McMurray

A McAlister

J McFarlane

J Kurley

August 31, 2020

Approved for public release. Distribution is unlimited. 


\section{DOCUMENT AVAILABILITY}

Reports produced after January 1, 1996, are generally available free via US Department of Energy (DOE) SciTech Connect.

Website www.osti.gov

Reports produced before January 1, 1996, may be purchased by members of the public from the following source:

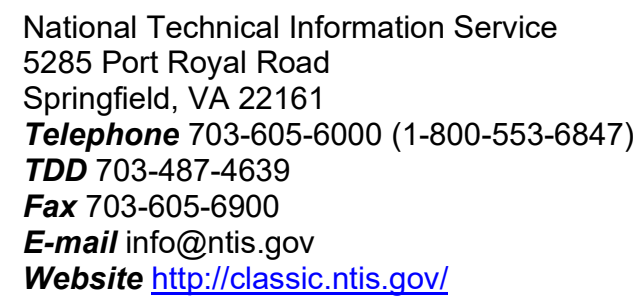

Reports are available to DOE employees, DOE contractors, Energy Technology Data Exchange representatives, and International Nuclear Information System representatives from the following source:

Office of Scientific and Technical Information

PO Box 62

Oak Ridge, TN 37831

Telephone 865-576-8401

Fax 865-576-5728

E-mail reports@osti.gov

Website http://www.osti.gov/contact.html

This report was prepared as an account of work sponsored by an agency of the United States Government. Neither the United States Government nor any agency thereof, nor any of their employees, makes any warranty, express or implied, or assumes any legal liability or responsibility for the accuracy, completeness, or usefulness of any information, apparatus, product, or process disclosed, or represents that its use would not infringe privately owned rights. Reference herein to any specific commercial product, process, or service by trade name, trademark, manufacturer, or otherwise, does not necessarily constitute or imply its endorsement, recommendation, or favoring by the United States Government or any agency thereof. The views and opinions of authors expressed herein do not necessarily state or reflect those of the United States Government or any agency thereof. 
Advanced Reactor Technologies Molten Salt Reactor Campaign

THERMAL ANALYSIS OF NON-ACTINIDE BEARING SALT

\author{
JW McMurray \\ A McAlister \\ J McFarlane \\ JM Kurley
}

Date Published:

August 31, 2020

Prepared by

OAK RIDGE NATIONAL LABORATORY

Oak Ridge, TN 37831-6283

managed by

UT-BATTELLE, LLC

for the

US DEPARTMENT OF ENERGY

under contract DE-AC05-00OR22725 



\section{CONTENTS}

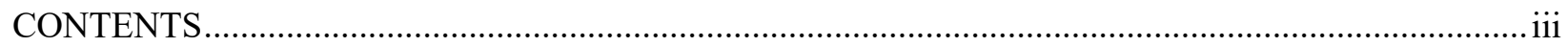

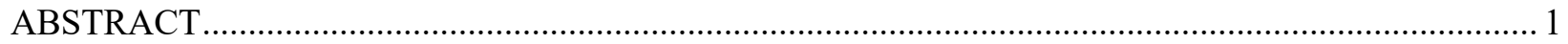

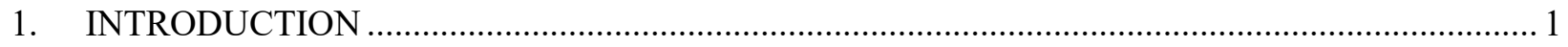

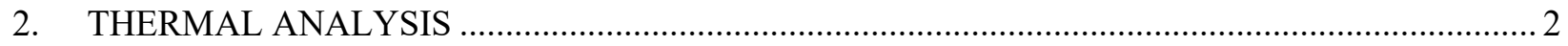

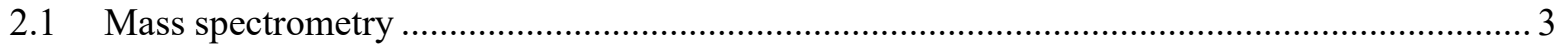

2.2 Mass loss Knudsen effusion............................................................................... 4

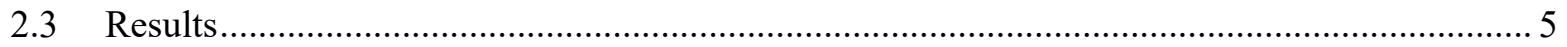

2.3.1 Comparison to the Molten Salt Thermodynamic Database .....................................5

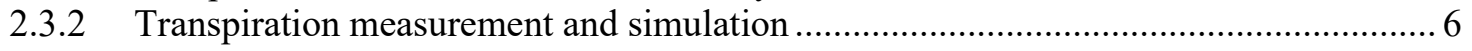

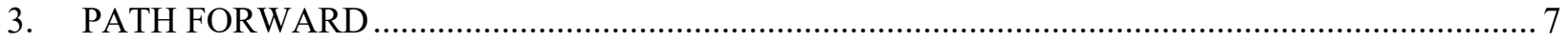

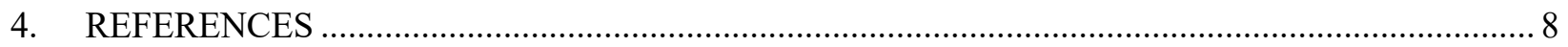




\begin{abstract}
The Netzsch STA 409 CD 403/5/G STA-MS Skimmer Coupling System was used to perform thermal analysis on FLiNaK to establish a method for characterizing vapor pressures over molten salts. The measurements include differential scanning calorimetry, thermogravimetry, and mass spectrometry to generate comprehensive thermochemical property data as stand-alone information to aid in MSR design and licensing as well as inputs into the Molten Salt Thermodynamic Database (MSTDB). The FY20 focus is to establish procedures and quantify uncertainty levels for measurements of non-actinide compositions for moving toward actinide bearing salt measurements in FY21.
\end{abstract}

\title{
1. INTRODUCTION
}

The Netzsch STA 409 CD 403/5/G STA-MS Skimmer Coupling System, hereafter referred to simply as the Skimmer, is shown in Figure 1. It was delivered to Oak Ridge National Laboratory (ORNL), installed, and operational in FY19. The equipment was verified to be functional by performing thermal analysis on a non-hazardous, well characterized standard, that is calcium salt of oxalate. In FY20, the objective was to develop a standard procedure and determine uncertainty levels for vapor pressure measurements of non-actinide salts. Eutectic FLiNaK, that is 46.5 LiF-11.5 NaF- $42.0 \mathrm{KF}$ mol \%, was selected to accomplish this since it is well characterized in the literature and requires minimal hazard controls. It is used to simulate the beryllium containing $2 \mathrm{LiF}_{-\mathrm{BeF}}, \mathrm{FLiBe}$, as it has similar physical properties. FLiBe has been proposed as a constituent of molten salt reactor carrier or coolant salt. The purified FLiNaK was purchased from Electrochemical Systems Inc (Oak Ridge, TN).

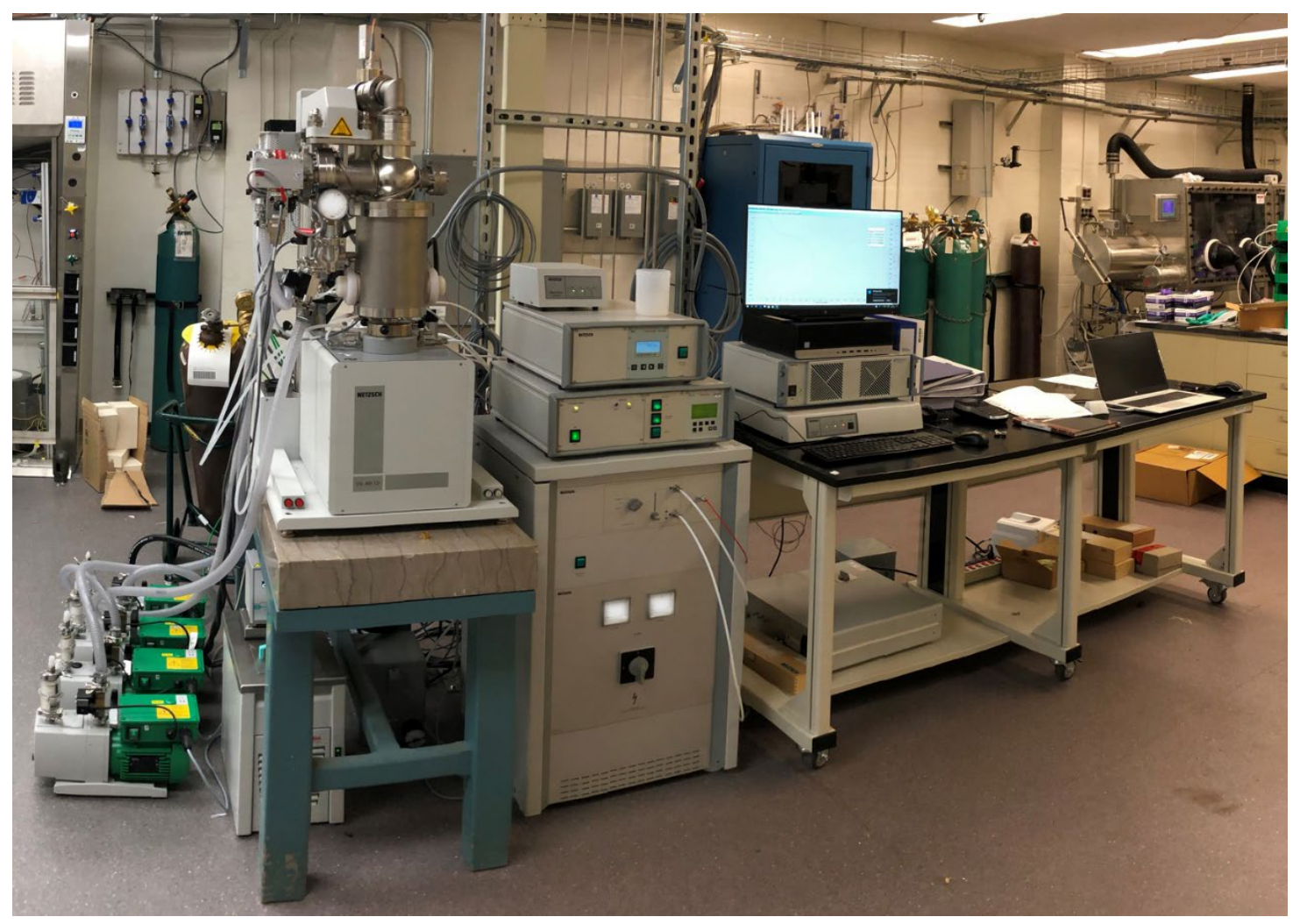

Figure 1. The Netzsch Skimmer at the Molten Salt Thermal Properties Laboratory at ORNL. 
In addition to vapor pressure measurements, specific heat of FLiNaK in a glassy carbon crucible was determined using a Netzsch Pegasus $404 \mathrm{C}$ differential scanning calorimeter. The details of those results can be found in [1].

\section{THERMAL ANALYSIS}

The Skimmer measures MS signals of gases up to $2000^{\circ} \mathrm{C}$ by using the shortest possible connection path between the cone and ion source as shown below. This overcomes the limitations of traditional MS transfer lines that operate at $\sim 300^{\circ} \mathrm{C}$ where many analytes condense and escape detection.

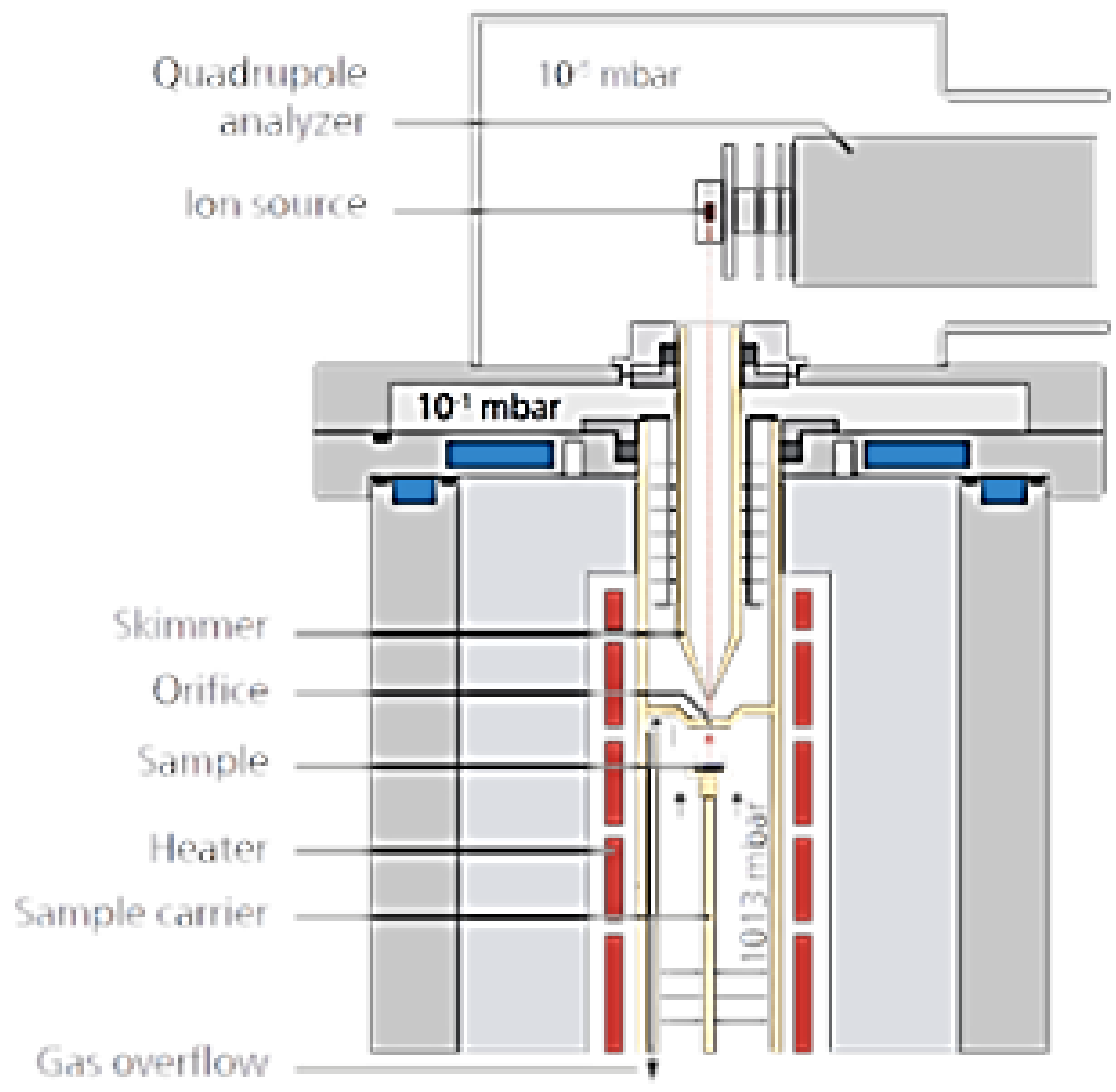

Figure 2. Schematic of the Skimmer illustrating the shortened, heated pathway that vapors over a sample travel to reach the Quadrupole Mass Spectrometer. Used by permission from Netzsch Gerätebau GmbH. 


\subsection{MASS SPECTROMETRY}

The Skimmer was used to determine the relative amounts of major gaseous species over FLiNaK as a function of temperature, with some assumptions. For example, the unless there is congruent vaporization, the composition of the molten salt will change. It is assumed, in this work, that the compositional change is negligible, although this can be tested with before and after analysis of the residue in the vessel. In principle, the ionization cross-section, fragmentation, ion-molecule reactions, sampling geometry of the mass spectrometer, and depletion of the condensed phase will affect the MS detection. However, for this work, it is assumed that the vapor pressure ratios correspond to the measured ion current intensity of each species and associated fragments. The subject of future investigations will focus on understanding the error associated with this approach based on a sensitivity analysis of compositional effects. Variation of the ionization energy can provide information on the origin of the species observed in the mass spectrometer, whether from primary or secondary ionization, or from ion-molecule reactions.

The mass spectrum for a ramp from room temperature to over $1000^{\circ} \mathrm{C}$ is shown in Figure 3. The measurement was made in flowing ultra-high-purity (UHP) Ar (supplied by Airgas) at $100 \mathrm{cc} / \mathrm{min}$. The spectra shows that the dominant species over FLiNaK are $\mathrm{KF}, \mathrm{NaF}, \mathrm{LiF}$, and $\mathrm{Li}_{2} \mathrm{~F}_{2}$. Results compare well with previous analyses [2-4]. The absolute value of the ion current signal for each species and associated fragments, were summed to determine the relative ratios. Thermogravimetry (TG) was then performed with the Skimmer and a specially designed graphite Knudsen cell (Figure 4). The details of this measurement are discussed in the next section. The ratios from the MS, the results from the TG coupled Knudsen effusion, and Eqn. 1were used to compute quantitative vapor pressures for $\mathrm{KF}, \mathrm{NaF}$, $\mathrm{LiF}$, and $\mathrm{Li}_{2} \mathrm{~F}_{2}$ over FLiNaK.

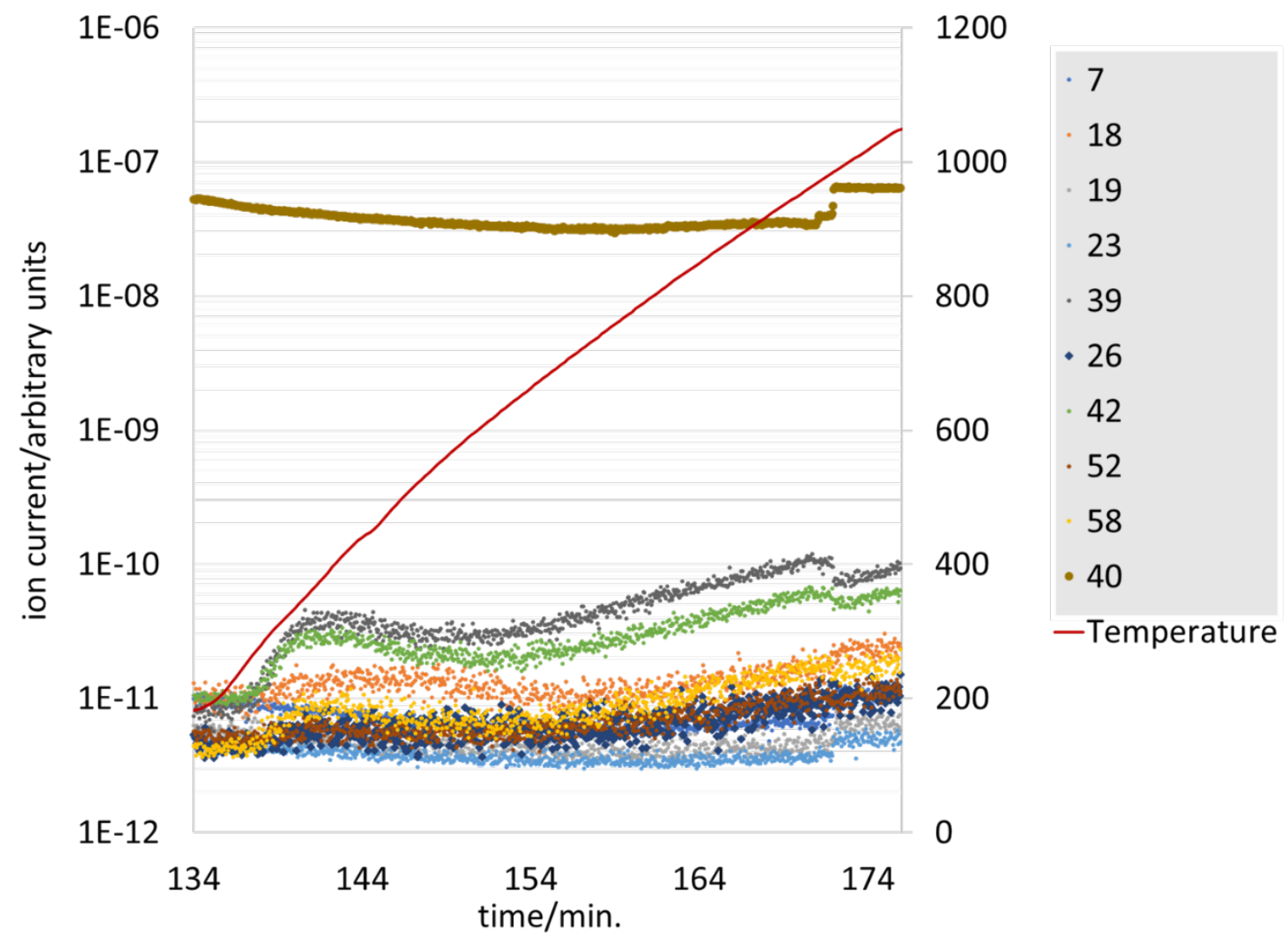

Figure 3. Mass to charge ratios from mass spectra are related to vapor species over the salt 


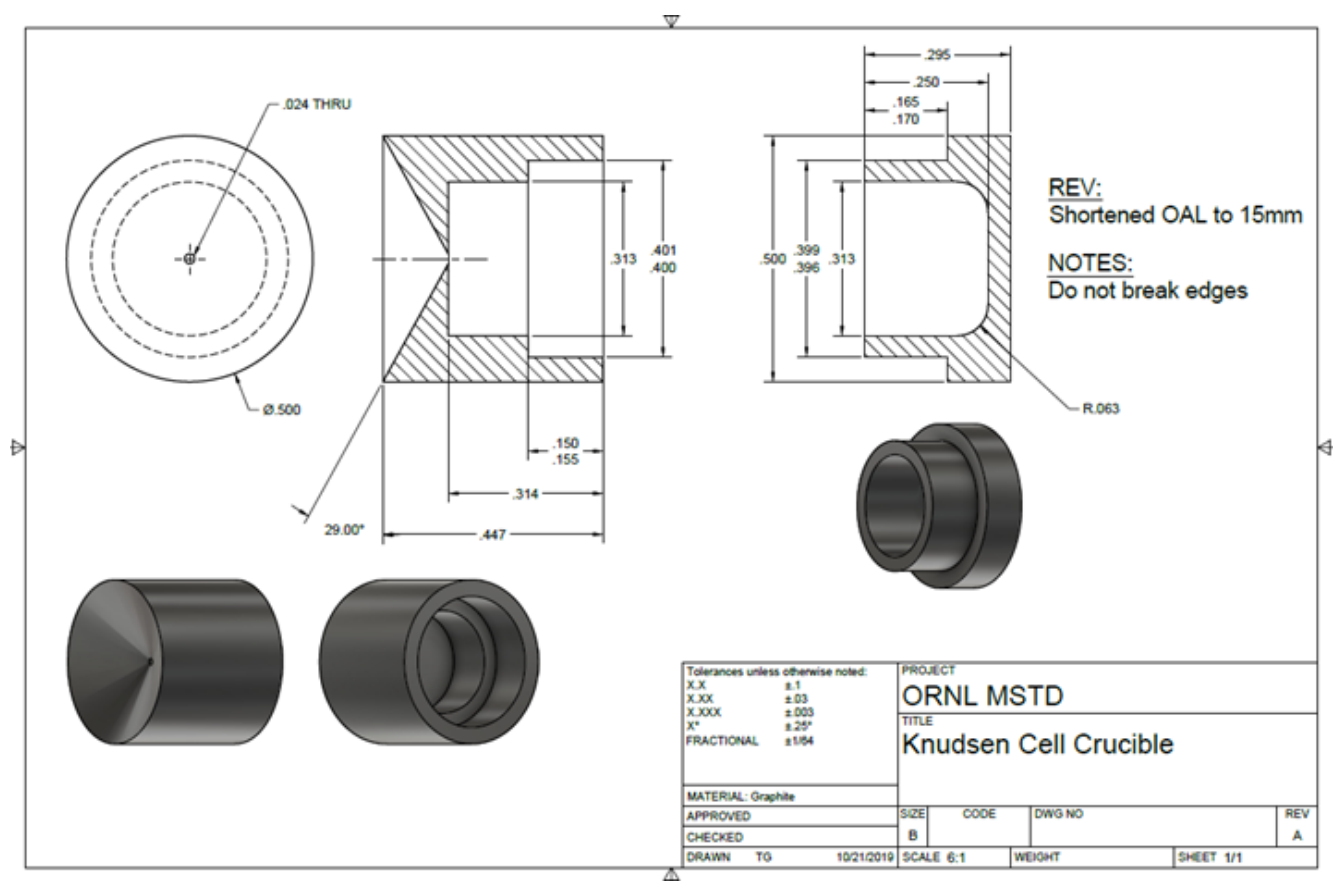

Figure 4. ORNL custom graphite Buchler cell for FLiNaK measurements.

\subsection{MASS LOSS KNUDSEN EFFUSION}

The Hertz-Knudsen-Langmuir equation [5] is:

$$
J=\sum_{i} \frac{m w_{i} \times p_{i}}{\sqrt{2 \pi \times m w_{i} \times R \times T}}
$$

where, $J$ is the flux of vapor species leaving the cell $R$ is the ideal gas constant, $T$ is the temperature in Kelvin. Further, $m w_{i}$ is the molecular weight and $p_{i}$ is the partial pressure of species $i$ that is also related to the activity of species $i$ as well as the components of species $i$ in the condensed phase. A customized Buchler type Knudsen cell was filled with FLiNaK and the weight change was measured in the Skimmer under high vacuum $\left(10^{-4} \mathrm{~Pa}\right)$ at a series of isothermal holds. Representative results at $720^{\circ} \mathrm{C}$ are shown in Figure 5. The slope of the line in the inset was determined using data analytics; it is the mass loss in $\mathrm{mg} / \mathrm{min}$ and is used with the cross-sectional area of the Knudsen orifice to determine the flux. This information combined with the ratios from the MS measurement at the same temperature allows each $p_{i}$ to be computed for $\mathrm{KF}, \mathrm{NaF}, \mathrm{LiF}$, and $\mathrm{Li}_{2} \mathrm{~F}_{2}$. 


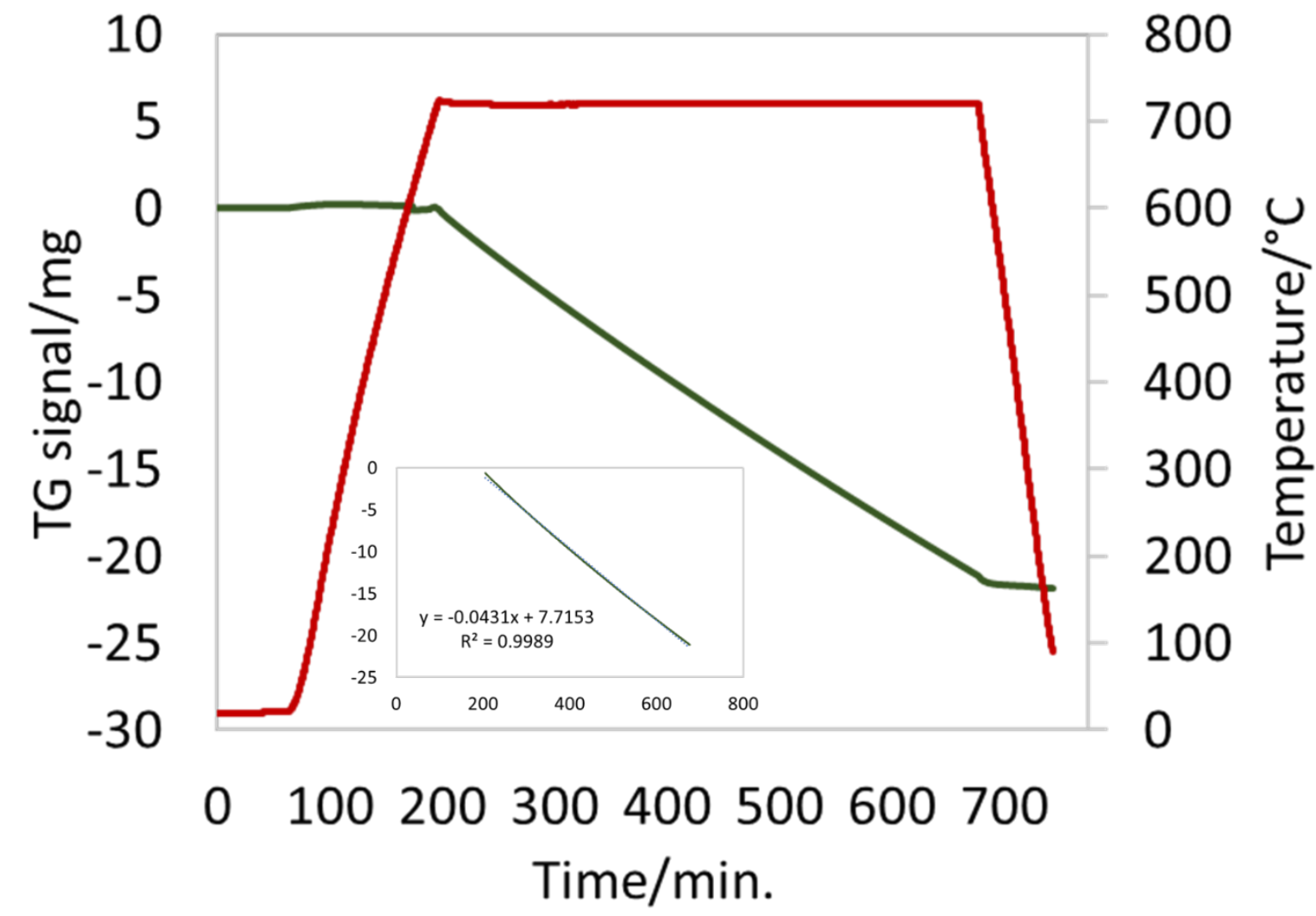

Figure 5. Mass loss data at $720^{\circ} \mathrm{C}$ for FLiNaK in the Knudsen cell under hard vacuum $<1 E-5 \mathrm{mbar}$

\subsection{RESULTS}

The technique has been applied to a range of materials, i.e ionic liquids [6-11]. To the authors' knowledge, it has never before been used to determine vapor pressures of molten salts relevant to nuclear reactors. To validate the approach, the results were compared to calculations using the Molten Salt Thermodynamic Database [12] and a transpiration type vaporization in the Skimmer.

\subsubsection{Comparison to the Molten Salt Thermodynamic Database}

In Figure 7, the solid lines are computed vapor pressures using the Modified Quasi-chemical Model [1315] from the Molten Salt Thermodynamic Database (MSTDB). The symbols are the results from the mass loss Knudsen effusion measurement. Good agreement can be seen. The comparison helps to validate the experimental approach. Since no vapor pressure values for FLiNaK were used to develop the models in MSTDB, it can be expected that some refinement would be necessary. Therefore, the results from this work can be used to further optimize the parameters in the MSTDB to better represent the measured values. 


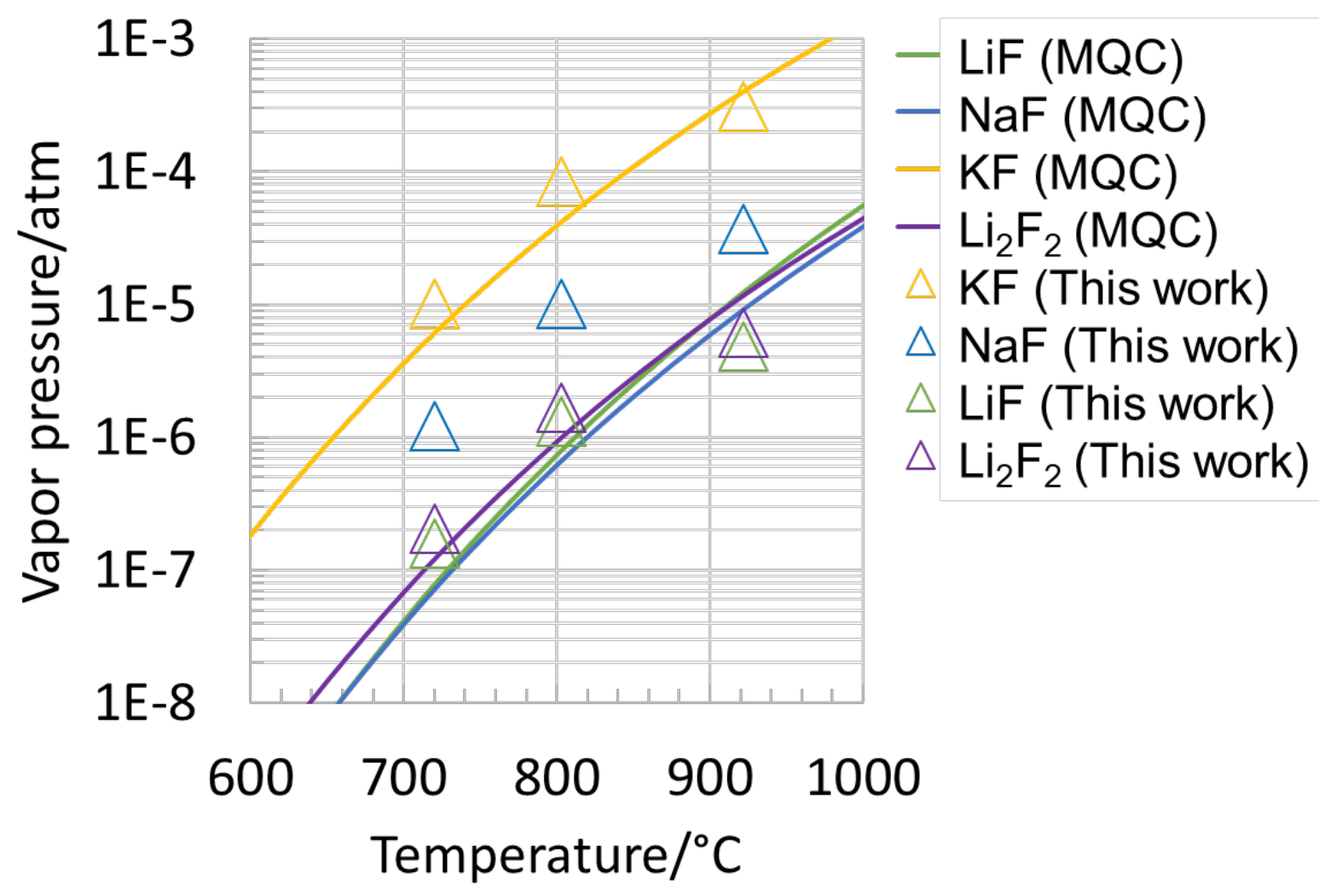

Figure 6. ORNL results are in good agreement with the current thermodynamic database but some minor refinement is needed.

\subsubsection{Transpiration measurement and simulation}

The transpiration technique [16] can also be used for vapor pressure determinations. Here it was employed to validate the MS coupled mass loss Knudsen results. The FLiNaK was loaded in an open graphite crucible and TG analysis was performed with the Skimmer system. For a true transpiration measurement, the flow regime for material and specific experimental condition, i.e. temperature, must found with a systematic approach, for this work a constant flow of $50 \mathrm{cc} / \mathrm{min}$ of UHP Ar was used based on experience with a similar instrument for $\mathrm{UO}_{2+x}$ [17] and reported literature [18]. An attempt was made to reproduce the temperatures reached during the mass loss Knudsen effusion measurements. While unsuccessful, the isothermal holds for $853^{\circ} \mathrm{C}$ and $928^{\circ} \mathrm{C}$ were close enough to perform a vaporization simulation using the partial pressures determined Knudsen effusion measurements at $803^{\circ} \mathrm{C}$ and $922^{\circ} \mathrm{C}$. The calculated and measured mass loss is compared in Figure 6 . There exists uncertainty regarding whether the flow rate falls within the equilibrium regime per a strict transpiration definition, however the close agreement between the observed and simulated results gives further confidence in the Knudsen effusion derived vapor pressure values. 


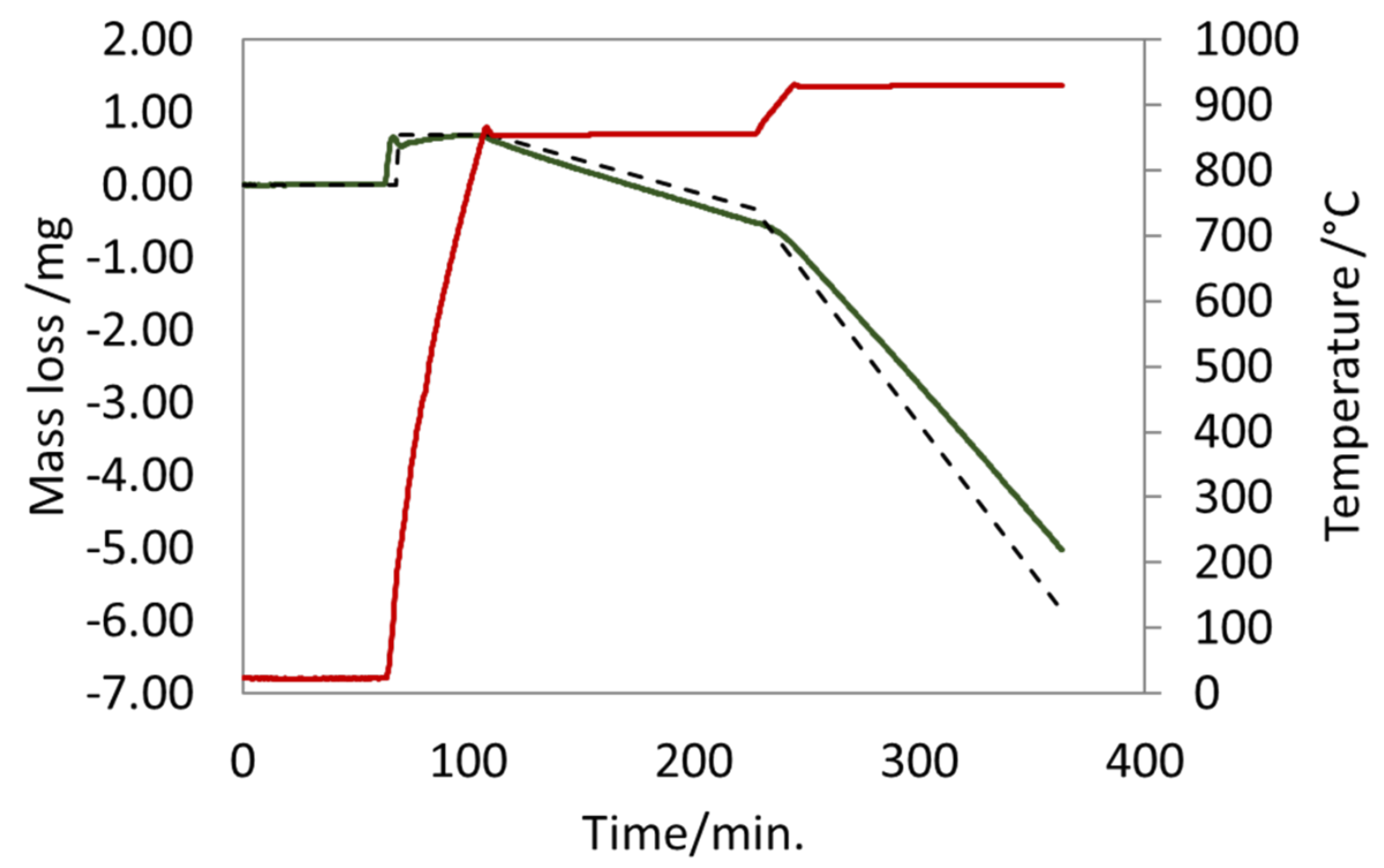

Figure 7. Simulated (dashed) and measured (solid, green) mass loss correspond to the left ordinate. The red line is the temperature read from the right ordinate.

\section{PATH FORWARD}

The subject of future investigations will focus on understanding the error associated with this approach based on a sensitivity analysis of compositional and instrumental effects, e.g. ionizer geometry and ionization energy. Measurements of other salts are planned. During the remainder of FY20, FLiNaK doped with Cs and I will be characterized. For FY21, planning is underway to perform thermal analysis of eutectic $\mathrm{NaCl}-\mathrm{KCl}$ and FLiBe. The transpiration technique, matching the temperatures to the Knudsen measurement, proved unsuccessful due to human error. It also requires an isothermal, systematic flow program to determine the equilibrium regime precisely. These two issues will be resolved to aid in validating the approach for quantitative vapor pressure analysis of molten salts using the Skimmer MS with mass loss Knudsen effusion. 


\section{REFERENCES}

[1] N. D. B. Ezell, R. Gallagher, N. Russell, A. Martin, J. W. McMurray, Thermophysical Property Measurements on Salt Mixture, Oak Ridge National Laboratory, ORNL/TM-2020/1633 (2020)

[2] M. Eisenstadt, G. Rothberg, P. Kusch, The Journal of Chemical Physics, 29 (4) (1958) 797-804.

[3] D. Hildenbrand, W. Hall, F. Ju, N. Potter, The Journal of Chemical Physics, 40 (10) (1964) 2882-90.

[4] M. Taira, Y. Arita, M. Yamawaki, The Open Access Journal of Science and Technology, 5 (5) (2017) $1-17$.

[5] B. V. L'vov, Thermal decomposition of solids and melts: new thermochemical approach to the mechanism, kinetics and methodology, Springer Science \& Business Media, 2007.

[6] E. H. Copland, N. S. Jacobson, Mass Spectrometry Handbook, 1143-80.

[7] G. Pound, J. Phys. Chem. Ref. Data, 1 (1) (1972) 135-46.

[8] J. Drowart, C. Chatillon, J. Hastie, D. Bonnell, Pure Appl. Chem., 77 (4) (2005) 683-737.

[9] D. H. Zaitsau, G. J. Kabo, A. A. Strechan, Y. U. Paulechka, A. Tschersich, S. P. Verevkin, A. Heintz, The Journal of Physical Chemistry A, 110 (22) (2006) 7303-6.

[10] A. Booth, T. Markus, G. McFiggans, C. Percival, M. Mcgillen, D. Topping, Atmospheric Measurement Techniques, 2 (2) (2009) 355-61.

[11] M. Hayashi, S. Maruyama, Alkylated diphenyl ether compound and lubricating oil containing said compound: Google Patents; 2013.

[12] J. W. Mcmurray, T. Besmann, J. Ard, S. Utlak, J. P. Lefebvre, Status of the molten salt thermodynamic database, MSTDB, Oak Ridge National Laboratory, ORNL/SPR-2019/1208 (2019) [13] A. Pelton, S. Degterov, G. Eriksson, C. Robelin, Y. Dessureault, Metallurgical and Materials Transactions B, 31 (4) (2000) 651-9.

[14] A. D. Pelton, P. Chartrand, Metallurgical and Materials Transactions A, 32 (6) (2001) 1355-60.

[15] A. D. Pelton, P. Chartrand, G. Eriksson, Metallurgical and Materials Transactions A, 32 (6) (2001) 1409-16.

[16] U. Merten, W. Bell, The Characterization of High-Temperature Vapors, In: JL Margrave editor, New York: Wiley; 1967.

[17] J. W. McMurray, The Journal of Chemical Thermodynamics, 95 (2016) 72-6.

[18] M. Ali, R. Mishra, A. S. Kerkar, S. R. Bharadwaj, D. Das, Journal of Nuclear Materials, 301 (2-3) (2002) 183-6. 